\title{
High Grade Encapsulated Papillary Carcinoma of Breast in a Young Female
}

\author{
Madiha Bilal Qureshi and Naila Kayani \\ Histopathology Section, Department of Laboratory Medicine, The Aga Khan University Hospital, Karachi, Pakistan
}

\begin{abstract}
Encapsulated papillary carcinoma (EPC) is a special type of papillary breast lesion known to be of low and intermediate grade. But recent data suggests existence of such tumors with high nuclear grade and mitotic index rendering them aggressive with chances of recurrence and lymph node metastasis which may alter the management of this tumor. Here, we present a case of a high grade encapsulated papillary carcinoma in a 22-year female who had a history of painful swelling in the upper outer quadrant of right breast with tender lymph nodes in the lower axilla. The subsequent radiologic findings showed a solid mass with cystic component and the patient underwent wide local excision along with excision of lymph nodes. Microscopy revealed a high-grade encapsulated tumor with papillary features; and a diagnosis of high grade encapsulated papillary carcinoma was given.
\end{abstract}

Key Words: High grade, encapsulated papillary carcinoma, breast.

How to cite this article: Qureshi MB, Kayani N. High grade encapsulated papillary carcinoma of breast in a young female. $J$ Coll Physicians Surg Pak 2019; 29 (Supplement 2):S114-S116.

\section{INTRODUCTION}

Papillary carcinoma accounts for less than $2 \%$ of breast carcinomas. Encapsulated papillary carcinoma (EPC) is regarded as a rare variant of papillary carcinoma. ${ }^{1}$ It usually occurs in old women. Clinically, it appears as a circumscribed round mass, variably associated with nipple discharge. ${ }^{2}$ Radiography typically demonstrates a mass within a cystically dilated space. Gross examination usually reveals a friable mass inside a cystic cavity. Microscopically, EPCs are surrounded by fibrous capsule with papillary proliferation of neoplastic epithelial cells of low to intermediate grade supported by fibrovascular stalks with absent myoepithelial cell layer within the papillae and around the periphery. ${ }^{2}$ Prognosis is usually favourable; however, a subset of these tumors shows high grade cytonuclear features, high mitotic index, focal micropapillary areas or extracellular mucin which renders them as aggressive tumors with potential for recurrence and metastasis. ${ }^{3-5}$

We present a case of 22-year female with swelling in the right breast upper outer quadrant for the last seven months.

\section{CASE REPORT}

A 22-year female presented with tender swelling in right breast upper outer quadrant for a period of seven months.

Correspondence to: Dr. Madiha Bilal Qureshi,Histopathology Section, Department of Laboratory Medicine, The Aga Khan

University Hospital, Stadium Road, Karachi, Pakistan

E-mail: madiha-shahid@hotmail.com

Received: January 23, 2019; Revised: April 07, 2019;

Accepted: April 20, 2019
The swelling was associated with fever, bodyache and palpable tender lymph nodes in the ipsilateral lower axilla. Ultrasound breast revealed a solid mass with cystic component.

The specimen received was coded as "Right breast, wide local excision with axillary lymph node dissection". It was a nodular non-skin covered fibroadipose tissue measuring $8.5 \times 8 \times 6.5 \mathrm{~cm}$ with attached irregular piece of adipose tissue measuring $9 \times 3.5 \mathrm{~cm}$ (Figure 1). Cut surface of the nodule revealed an encapsulated cystic friable lesion measuring $6 \times 6 \mathrm{~cm}$. It had a tan to pale yellow appearance. Grossly, it was $0.2 \mathrm{~cm}$ from the outer painted fat. A total of 11 lymph nodes were recovered from the attached adipose tissue.

Microscopy showed an encapsulated lesion composed of large nests and aggregates of cells supported by fibro-vascular stalks. The cells were moderately pleomorphic with vesicular nuclei, conspicuous nucleoli and scant to moderate eosinophilic cytoplasm. Brisk mitotic activity (up to 33 mitoses/10 HPF), necrosis and fibrosis were also seen (Figure 2). The tumor was graded as grade III (tubule, 3; pleomorphic, 3; mitotic count, 3) according to Modified Bloom and Richardson grading system. Immunostaining for smooth muscle actin (SMA) showed loss of myoepithelial cells within the lesion and at the periphery. Receptor status showed weak estrogen receptor positivity; whereas, progesterone receptor and HER-2 neu were negative. All lymph nodes were negative. Based on all these combined features, this was diagnosed as high grade EPC of right breast. A comment was given regarding stage that it was inappropriate to stage encapsulated papillary breast 


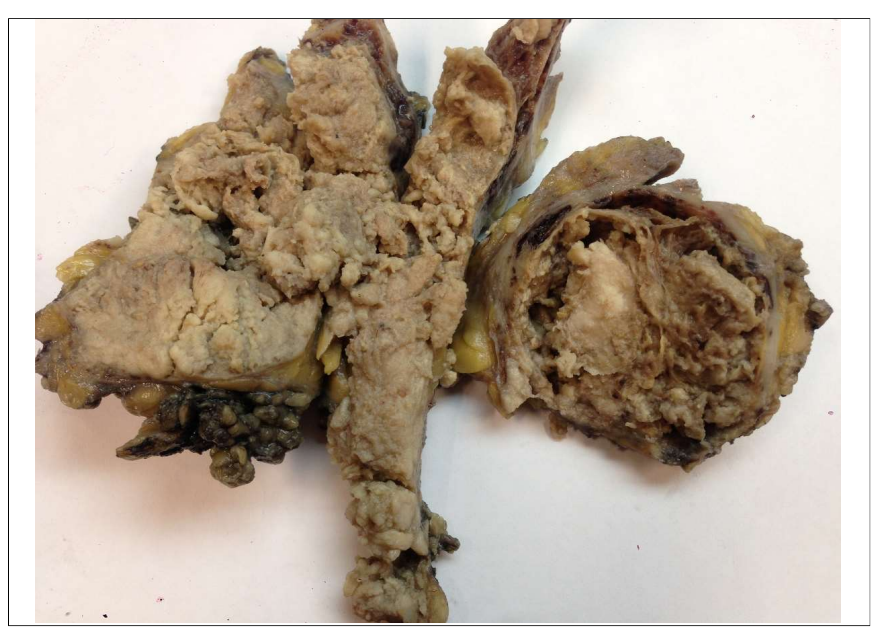

Figure 1: Encapsulated circumscribed tumor with gross papillary configuration and surrounding breast tissue.

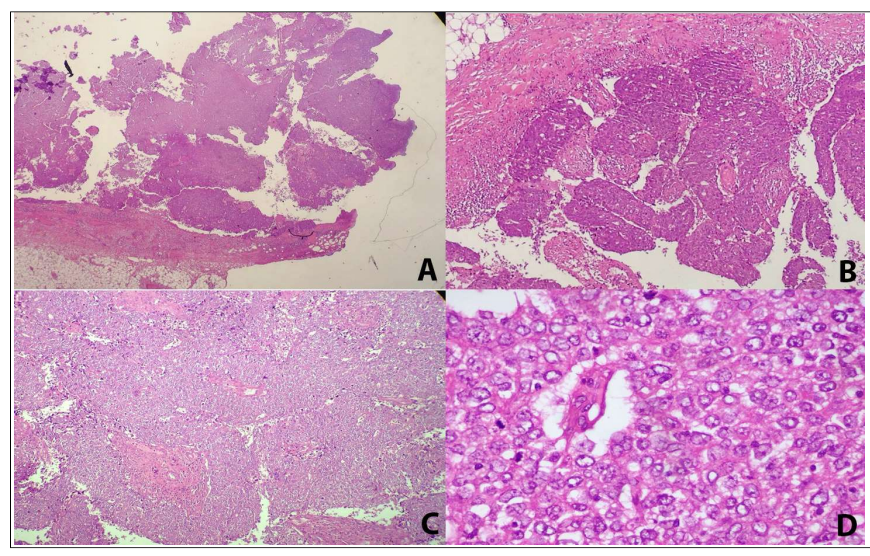

Figure 2: (A) Papillary lesion surrounded by fibrous capsule (H\&E stain $2 x$ ). (B \& C) Papillary tumor with prominent fibrovascular cores (H\&E stain 4x \& 10x).

(D) Moderately atypical nuclei with frequent mitotic figures (H\&E stain 40x).

carcinoma with high grade features as per current WHO staging of breast carcinomas. Patient received further treatment as chemo-radiation and after a follow-up of one and a half year, patient was disease-free. ${ }^{2}$

\section{DISCUSSION}

Previous studies have shown that 2.5 to $14 \%$ of pure EPCs are high grade. Several recent studies have reidentified such tumors with tendency to develop local stromal/muscle infiltration and metastasis. 5-7 Though EPCs have a thick capsule, but it is a result of reactive process rather than the ducts' basement membrane expansion. 6 Therefore, some authors consider it as a non-conventional invasive form of breast carcinoma. ${ }^{8}$ Our case was a pure encapsulated one, but had high nuclear grade, pleomorphism and brisk mitotic index which do not justify to stage it as Tis as per WHO guidelines. There is another recent study in which 12 such tumors were identified, out of which 10 had outcome data. One of these patients developed recurrence and distant metastasis that ended in cancerrelated death of the patient and seven cases had follow- up of only less than two years. Sixty-eight percent of these cases were hormone receptor negative and two cases even showed necrotic foci. Few cases were positive for other markers, namely, cytokeratin $5 / 6$ and EGFR.4,9 In another study by Lefkowitz et al. on 77 cases, three patients with pure EPC without stromal invasion developed metastasis. 10

Hence, classification, staging and management of this subset of EPCs with aggressive features should be revisited in order to justify the aggressiveness of such tumors at clinical level. EPC is a heterogeneous tumor with low grade tumors at one end and high grade with aggressive features at the other. ${ }^{11} \mathrm{We}$ recommend characterisation of high grade EPCs and suggest further studies to understand the nature and behaviour of such tumors.

\section{PATIENT'S CONSENT:}

Informed consent was taken from the patient.

\section{CONFLICT OF INTEREST:}

Neither of the authors have any conflict to declare.

\section{AUTHORS' CONTRIBUTION:}

$M B Q$ : Drafted the case summary and discussion, drafted and edited the manuscript.

NK: Established and confirmed the diagnosis, drafted the manuscript and references.

\section{REFERENCES}

1. Tan PH, Schnitt SJ, van de Vijver MJ, Ellis IO, Lakhani SR. Papillary and neuroendocrine breast lesions: The WHO stance. Histopathol. 2015; 66:761-70.

2. Organization WH. The Selection and Use of Essential Medicines: Report of the WHO Expert Committee, 2015 (including the 19th WHO Model List of Essential Medicines and the 5th WHO Model List of Essential Medicines for Children): World Health Organ; 2015.

3. Zhang C, Zhang P, Hao J, Quddus MR, Steinhoff MM, Sung CJ. High nuclear grade, frequent mitotic activity, cyclin D1 and p53 overexpression are associated with stromal invasion in mammary intracystic papillary carcinoma. Breast J 2005; 11:2-8.

4. Rakha EA, Varga Z, Elsheik S, Ellis IO. High-grade encapsulated papillary carcinoma of the breast: An under-recognized entity. Histopathology 2015; 66:740-6.

5. Wynveen CA, Nehhozina T, Akram M, Hassan M, Norton L, Van Zee KJ, et al. Intracystic papillary carcinoma of the breast: An in situ or invasive tumor? Results of immunohistochemical analysis and clinical follow-up. Am J Surg Pathol 2011; 35:1-14.

6. Rakha EA, Gandhi N, Climent F, van Deurzen CH, Haider SA, Dunk L, et al. Encapsulated papillary carcinoma of the breast: an invasive tumor with excellent prognosis. Am J Surg Pathol 2011; 35:1093-103.

7. Duprez R, Wilkerson PM, Lacroix-Triki M, Lambros MB, MacKay A, Hern RA, et al. Immunophenotypic and genomic characterization of papillary carcinomas of the breast. $J$ Pathol 2012; 226:427-41. 
8. Esposito NN, Dabbs DJ, Bhargava R. Are encapsulated papillary carcinomas of the breast in situ or invasive? A basement membrane study of 27 cases. Am J Surg Pathol 2009; 131:228-42.

9. Lanzafame S, Emmanuele C, Torrisi A, Magro G. Correlated expression of BCL-2 protein, estrogen receptor, cathepsin D and low growth fraction (PCNA) in intracystic papillary breast carcinoma. Pathol Res Pract 1998; 194:541-7.
10. Lefkowitz M, Lefkowitz W, Wargotz ES. Intraductal (intracystic) papillary carcinoma of the breast and its variants: A clinicopathological study of 77 cases. Hum Pathol 1994; 25: 802-9.

11. Tariq N, Mamoon N, Usman M, Ali Z, Nazir I. Encapsulated papillary carcinoma (EPC) of breast: A clinical, pathological and immunohistochemical analysis of eight cases. JPMA 2016; 66:1490-3. 